work of an educational expert who has certain ideals, and does not hesitate to show how far existing conditions differ from them. Strong opinions are given on the vexed question of the London hospital medical schools, and on the constitution of London University. How far the recommendations are practical is a question that must be left for the authorities concerned to decide. It is certainly desirable that London as a teaching centre of medicine should not occupy a position inferior to the great schools of Berlin, Vienna, and Paris.

Whatever we may think of some of the author's criticisms, one cannot but admire the ability and thoroughness with which he has collected information and drawn up his report. Educationists generally, and medical teaching authorities in particular, owe a debt of gratitude to the Carnegie Foundation for the Advancement of Teaching.

\section{LIQUID CRYSTALS AND THE X-RAY WORK.}

I $N$ two memoirs contributed to the current volume of the Verhandlungen des Naturwissenschaftlichen Vereins, Karlsruhe, Prof. O. Lehmann gives a valuable summary of his wellknown researches on the so-called liquid crystals, and reviews the proofs now available of molecular structure and of the operation of molecular forces, and especially the tangible proofs of the actual existence of molecules. Naturally, the most interesting part of such a communication from Prof. Lehmann is the expression of his views concerning the most recent of such proofs, afforded by the experimental work of Laue, Friedrich, and Knipping with X-rays and crystals at Munich and Zurich. The events leading up to this remarkable development are clearly indicated, and their individual significance emphasised. From the initial stages of the kinetic theory of gases in the days of Count Rumford and Robert Mayer-the former of whom was connected with Munich, and is there represented by a fine statue-to the reflection of X-ray electromagnetic waves from the invisible parallel planes of atoms in the interior of a crystal, and the impression of the systematic symmetry of the crystal on a photographic plate by the reflected rays, is a long step.

It will be with universal consent that Prof. Lehmann hails this new work as of richest consequence not only to crystallography, but to general physics. He considers it the first practical proof of the existence of those molecular forces which he has so long contended for as causing the deposition, layer upon layer in regular order, of the chemical molecules in their erection of the edifice of a crystal-that is, in the production of a three-dimensional grating or "space-lattice."

One of the surest signs of the magnitude of the discovery made at Munich is the fact that the experiments, as on the occasion of the discovery of radium, are being repeated and extended by numerous workers all over the world, as the columns of NATURE, in which many of the results NO. 2286, VOL. 9I] have been described, have lately abundantly testified.

It is a generally accepted maxim amongst men of science that the pioneer of a new discovery should be permitted to work out undisturbedly its further development, and it is sincerely to be hoped that Prof. Laue and Drs. Friedrich and Knipping will be able to carry their work to its logical conclusion. The bearing of the discovery on Prof. Bragg's theory of X-rays has, however, fully justified its further independent investigation by him and by his son, Mr. W. L. Bragg, who has crystallographic knowledge, and has added very considerably to the subject, both by further experiments and by an explanation which agrees with the crystallographic facts in a most remarkable manner. There are indications that the near future will see a surprising further development in the direction of arriving at the absolute dimensions of the cells of the space-lattice-that is, of the actual distances separating the chemical atoms, thus converting the topic axial ratios, which have been so useful a conception for affording us the relative dimensions of the cells in related compounds, into absolute spacial values. Moreover, the dimensions of the material parts of the atoms themselves appear likely to be also determinable within definite narrow limits, for the reflector, the atom, must be larger than the wave reflected, and it is now clearly proved that an ordinary reflection, and not a diffraction effect, is in question.

Another secondary result is that the intensity of the reflection is proving a direct function of the density with which the atoms are strewn in the reflecting plane, thus affording us an experimental means of carrying out Prof. von Fedorow's quest for the primary facial planes, so as to arrive at a proper descriptive setting for the crystal; for these primary planes, sometimes obscured by fortuitous better development of other planes on the exterior of the crystal, are invariably those most densely strewn with the atomic points.

For a discussion of the physics of the whole subject, especially as regards the position immediately before the Munich discovery, the two memoirs of Prof. Lehmann forming the subject of this notice may with advantage be consulted. A brief abstract of some of the most recent work of $\mathrm{Mr}$. W. L. Bragg will be found in the report of the proceedings of the Mineralogical Society of June 17 (see Nature of June 26, p. 44I).

\section{A. E. H. Tutton.}

\section{THE PILTDOWN SKULL.}

$\triangle$ MONG the questions discussed by the anatomiA cal section of the International Congress of Medicine was the date and reconstruction of the famous Piltdown skull. At South Kensington the fossil portions of the skull have been put together by Dr. Smith Woodward so as to represent a being partly ape, partly human, and named Eoanthropus dawsonii. From this model the brain gives a capacity of 1076 c.c.--an amount 